\title{
Hydrodynamic impact and power production of tidal turbines in a storm surge barrier
}

\author{
Tom S. D. O'Mahoney, Anton de Fockert, Arnout C. Bijlsma and Pieter de Haas
}

\begin{abstract}
To estimate the impact on energy production and environment of tidal turbines placed in the Eastern Scheldt Storm Surge Barrier a Computational Fluid Dynamics (CFD) study has been carried out on the additional head differences induced by the turbines.

The CFD model focusses on a single gate opening of the Storm Surge Barrier and includes half of the adjoining gates on either side. In this $40 \mathrm{~m}$ wide Gate a $1.2 \mathrm{MW}$ array existing of five Tocardo $\mathrm{T} 2$ tidal turbines has been installed as part of a demonstration project in 2015.

Transient computations of the barrier with and without the turbine array were carried out for a range of quasi stationary tidal phases. The turbines are resolved in detail as rotating equipment: real-time rotation of the turbine blades (involving the displacement of the mesh nodes in an unsteady setting) is implemented, and torque and thrust for the prescribed speed of rotation is provided as output. The results for velocity, power and thrust are compared with field experiments to validate the model.

Based on these computations an estimate of the effect of turbines on the discharge capacity of the storm surge barrier is given. This information will be used to parameterize the tidal turbines in the far-field hydrodynamic model of Eastern Scheldt estuary for the ultimate assessment of the effect of tidal turbines on energy production and on the environment.
\end{abstract}

Keywords-CFD validation, Tidal Turbines, Hydraulic Structure, Free Surface Flow

\section{INTRODUCTION}

$\mathrm{T}_{6}$ HE Eastern Scheldt Storm Surge Barrier consists of 62 individual gates, and is constructed of concrete pillars, top beams and sill beams connecting to a rockfill sill construction and about $600 \mathrm{~m}$ of bed protection on both sides, see [1]. During ebb and flood the maximum head difference over the barrier is about $1 \mathrm{~m}$, with maximum velocities of $4 \mathrm{~m} / \mathrm{s}$ and higher, making it an ideal site for the generation of tidal stream energy.

In 2015 an array of five tidal turbines was deployed in Gate \#08 of the Roompot Section of the barrier in the

Manuscript received 16 March; accepted 30 March; published 30 November, 2020. This is an open access article distributed under the terms of the Creative Commons Attribution 4.0 licence (CC BY https://creativecommons.org/licenses/by/4.0/). This article has been subject to single-blind peer review by a minimum of two reviewers. The work is part of the Dutch Marine Energy Centre project funded by the European Regional Development Fund and co-financed by the Province of Noord-Holland. framework of a tidal power pilot project. This project initiated the development of numerical modelling tools to assess the effects of the tidal turbines in this type of barrier, which need to be determined as part of the permit process. Previously, the CFD modelling of a tidal turbine in the proximity of the free surface was addressed, [2]. As a second step, the CFD modelling of the flow through the gates of the barrier (without turbines) was studied and compared with field measurements of ADCP horizontal and vertical profiles in the gate opening [3].

Analysis of the performance of tidal turbines has been conducted with BEM methods ([4,5]), CFD with frozen rotor [6] or actuator disc [7,8]. More recently CFD methods with rotating turbine blades in a sliding mesh configuration have been used to give a more detailed view of the flow field and turbulence at the inlet and wake of the turbines. Most experiments [9-12] consider isolated turbines at lab scale for a marine current application where

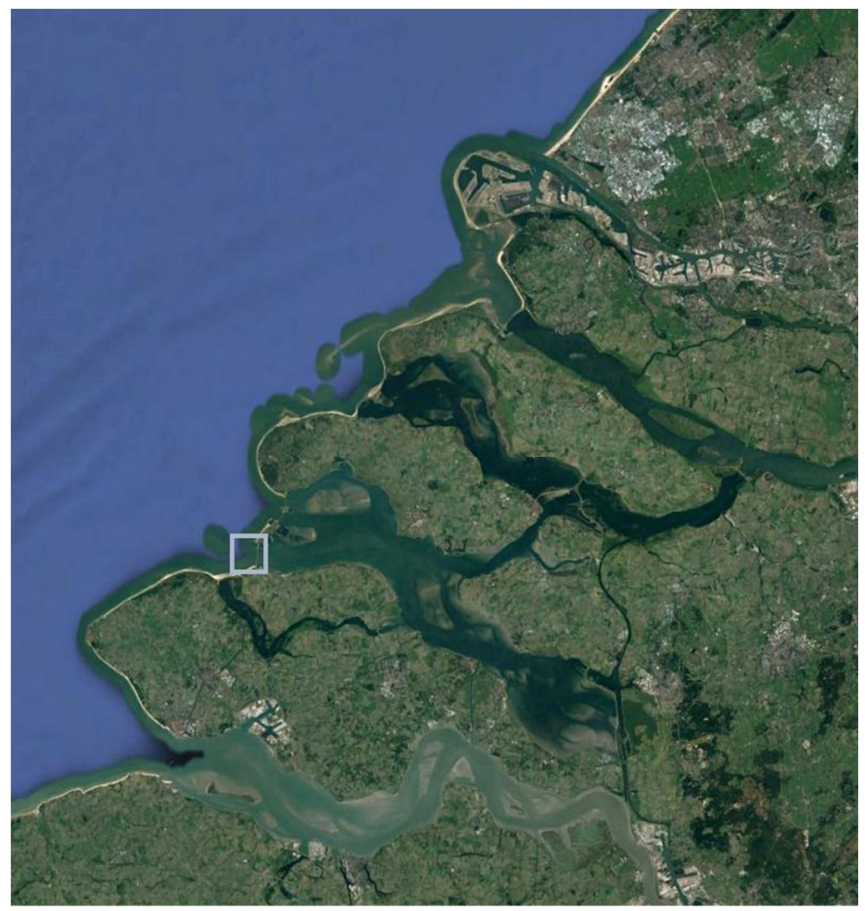

Fig. 1. Location of Gate+08 of the Roompot section of the Eastern Scheldt Barrier, shown on a satellite image (source: Google Earth)

T. S. D. O'Mahoney, A. de Fockert, A. C. Bijlsma, Deltares, Boussinesqweg 1 2629 HV Delft, The Netherlands (e-mail: tom.omahoney@deltares.nl, anton.defockert@deltares.nl, arnout.bijlsma@deltares.nl). P. de Haas, formerly Tocardo Tidal Power BV, Sluiskolkkade 2, 1779 GP, Den Oever, The Netherlands (e-mail:pdhaas@haske.net). Digital Object Identifier https://doi.org/10.36688/imej.3.127-136 
the flow is unidirectional. Subsequently, CFD validation efforts have therefore mostly concentrated on such situations. ([13-16]). Very few studies [17] have studied flow directionality. As the turbines in all these studies are isolated the blockages are relatively low (from $6 \%$ in [8], $12 \%$ in $[10]$, to $17 \%$ in $[18,19])$, although in one study a very high blockage was used [20]. Higher blockages have also been studied for cross flow turbines [21]. However, turbines located in a Storm Surge Barrier will have a higher blockage than those available in this literature.

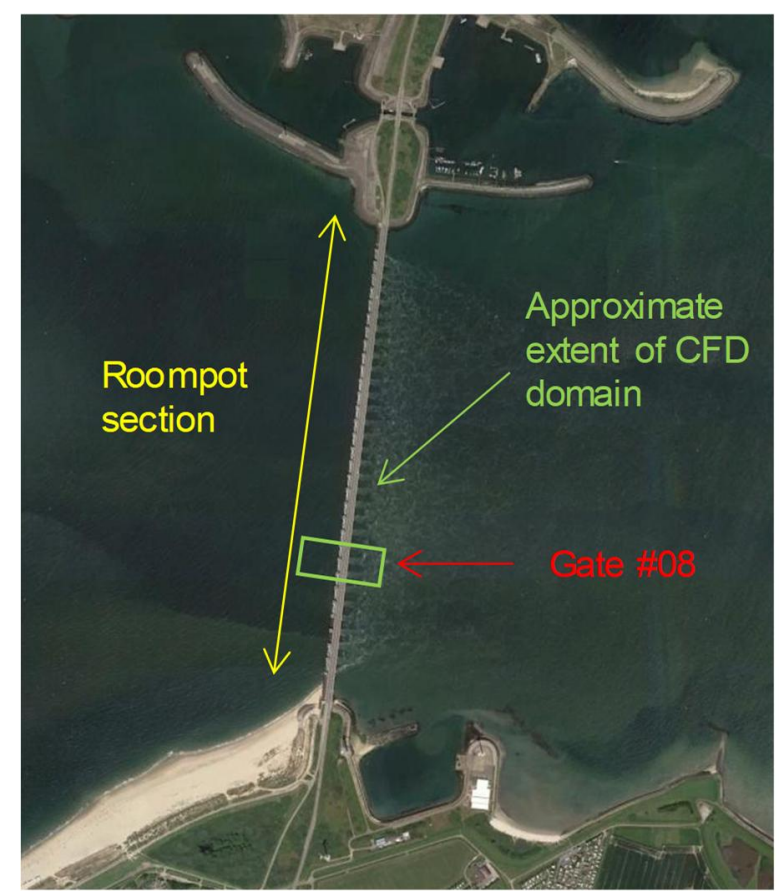

Fig. 2. Detail image of the Roompot section with the location of Gate\#08 (in red) and the approximate extent of the CFD domain (in green)

Similarly, the location of turbines in a pre-existing hydraulic structure leads to complex inflow conditions and interactions with the structure. Some authors have shown the importance of inflow velocity profile and inflow turbulence on turbine performance, wake development and the performance of CFD models [7, 22, 23]. The interaction with other turbines in arrays, both in terms of performance and wake recovery, has been studied but only in the absence of other structures [24-27]. Similarly an uneven bathymetry is often not included although the probable importance is stressed [12]. Field measurements in a real bathymetry have been made [28], on a site before turbine installation, and consequently lab scale measurements were scaled up for the CFD simulations with a turbine [16]. Alternatively the CFD has been performed at full-scale with measured inflow profiles [29]. The most recent work has measured in the field around the turbine fence in the Eastern Scheldt Barrier [30].

The aim of the current paper is to combine the modelling of bathymetry, surrounding structures and rotating blades to simulate a field scale tidal turbine array with high blockage owing to its location in a Storm Surge Barrier. Comparison with field scale measurements at the location of the turbines, with and without turbines is made in order to validate the CFD model. The CFD results give information about the interaction of the wake with that of the barrier and bathymetry, in terms of head difference and turbulence, and can help to inform modelling efforts at a larger system scale, which would be used for environmental impact assessments.

\section{MethodOlOGY}

The approach that has been taken in this study involves the comparison of CFD simulations with field measurements of velocity profiles, power and thrust in order to validate a numerical modelling approach. The simulations and measurements are made for situations in with and without turbines. Subsequently, the validated CFD model is used to calculate the effect of the presence of the turbines on the discharge characteristics (discharge coefficient) of the barrier, something which is not directly measured. The numerical tool would then also be available to study the effect on the flow field, velocities and turbulence near the bed, and on the bed protection. This section gives a short summary of the available measurements and the conditions used for the CFD model.
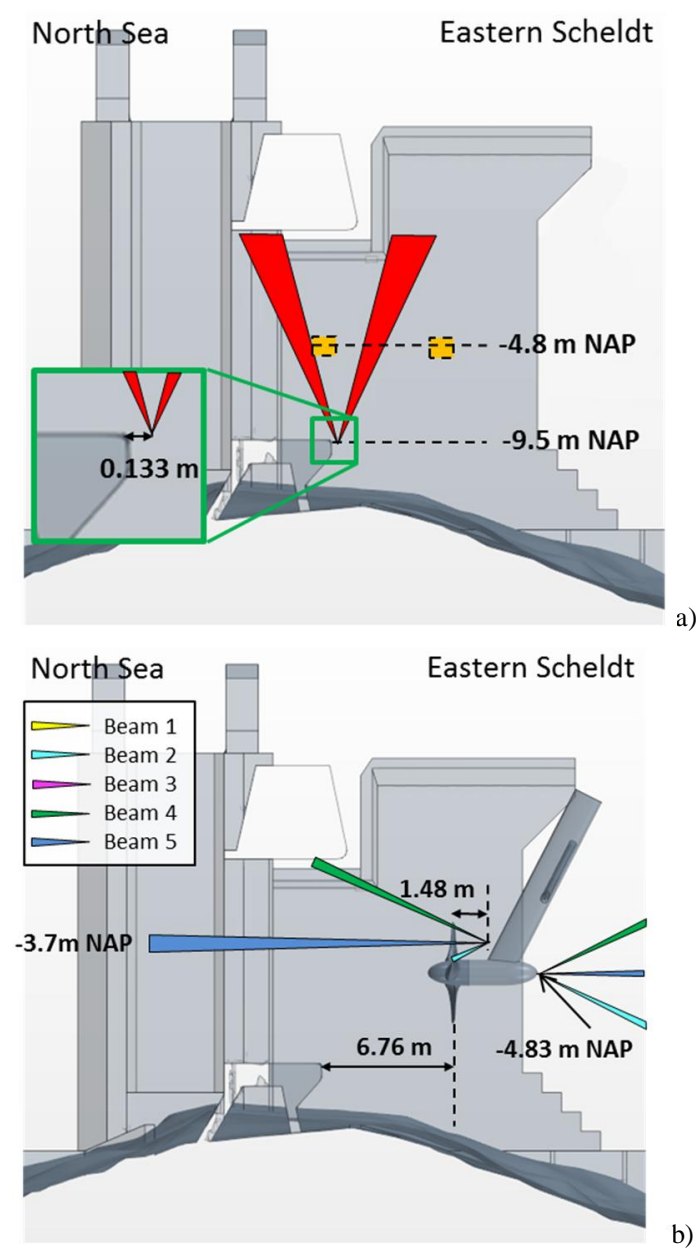

Fig. 3. Overview of the ADCP measurement: a) in 2011 without turbines and b) in 2015/2016 mounted from the turbines. Beams 1 and 3 are in the horizontal plane

\section{A. Velocity measurements}

ADCP measurements have been carried for both the situation before turbine deployment (2011) and during turbine deployment $(2016,2017)$. The locations of the 
measurements are shown in Figure 3. The vertical locations are given relative to Amsterdam Ordinance Datum (NAP) which is approximately mean sea level.

In 2015, 5 turbines were installed on the Eastern Scheldt side of Gate \#08 of the Eastern Scheldt Barrier Roompot section. The middle and outer turbines were equipped with two ADCP's, one pointed forwards (towards the North Sea) and one pointed backwards (towards the Eastern Scheldt), see Figure 3. The ADCP devices measure along 1 beam by default but have also been used to perform 5-beam measurements. Different periods have been measured. The performance of this type of turbine in isolation has been studied previously [2].

TABLE I

SUMMARY OF THE CONDITIONS USED FOR THE ANALYSIS

\begin{tabular}{lllll}
\hline \multirow{2}{*}{ Tide } & $\begin{array}{l}\text { Case } \\
\text { Number }\end{array}$ & $\begin{array}{l}\text { Water level } \\
\text { North Sea } \\
\text { w.r.t. NAP }\end{array}$ & $\begin{array}{l}\text { Water level } \\
\text { Eastern Scheldt } \\
\text { w.r.t. NAP }\end{array}$ & $\begin{array}{l}\text { Head } \\
{[\mathrm{m}]}\end{array}$ \\
\hline \multirow{2}{*}{ bbb } & NT,1MT.1 & 0.93 & 1.13 & -0.20 \\
& NT.2MT.2 & 0.68 & 1.00 & -0.32 \\
Flood & NT.3 WT.3 & -0.57 & -0.77 & 0.20 \\
& NT.4MT.4 & 1.12 & 0.57 & 0.55 \\
\hline
\end{tabular}

NT represents No Turbines, WT represents With Turbines

For each measurement a median is made over a number of tidal cycles of the measured variable (velocity, turbine RPM, turbine power or thrust) at each head to give a relation between the head difference and the median of the measured variable. The measured results shown in this paper are therefore the median values of the moments in the tidal cycles for which the heads are those as given in Table 1. For each head there are two moments in the tidal cycle at which it occurs; at the start and end of the tidal phase. Because of the inertia in the system the velocities at the end of the tidal phase are higher than at the start. These two moments are given separately in the results section of this paper.

The four cases chosen for this study include two ebb cases and two flood cases. The four cases are moments in the tidal cycle at which the ADCP data has been analysed. The range of the water levels and heads is determined by the range of ADCP data for which a positive quality check is available. They do not cover the entire range of operation of the turbines.

\section{B. Power measurements}

The generated power of the turbines has been analysed in a similar way to that of the rotation rates; giving a median power over many tidal cycles as function of the head difference. The resulting power for the head differences in each of the simulation conditions is given in

TABLE 2

SUMMARY OF THE MEASURED POWER OF THE TURBINES

\begin{tabular}{lllllll}
\hline \multirow{2}{*}{ Tide } & Case & $\begin{array}{l}\text { T1 } \\
{[\mathrm{kW}]}\end{array}$ & $\begin{array}{l}\text { T2 } \\
{[\mathrm{kW}]}\end{array}$ & $\begin{array}{l}\text { T3 } \\
{[\mathrm{kW}]}\end{array}$ & $\begin{array}{l}\text { T4 } \\
{[\mathrm{kW}]}\end{array}$ & $\begin{array}{l}\text { T5 } \\
{[\mathrm{kW}]}\end{array}$ \\
\hline \multirow{2}{*}{ Ebb } & WT.1 & 17.16 & 16.11 & 14.61 & 15.65 & 13.17 \\
& WT.2 & 36.38 & 34.86 & 33.45 & 34.80 & 33.03 \\
\multirow{2}{*}{ Flood } & WT.3 & 50.51 & 51.06 & 48.10 & 50.20 & 51.05 \\
& WT.4 & 219.99 & 223.28 & 214.06 & 217.36 & 222.02 \\
\hline
\end{tabular}

Table 2. The power generated in the simulations is not specified but is a result of the simulation. The moment and force on the turbines is a direct output from the simulations, calculated by Star-CCM+as an integration of pressure across the surface of the blades. The information of the measured power is used for comparison with the CFD in the results section. The values as specified in Table 2 are measured power values to the rotor after being corrected for the system losses.

It was seen that the power that is generated at the start of the tidal phase is significantly lower than at the end of the tidal phase. This is most likely the result of the approach flow towards the turbines, which for ebb is straighter at the end of the tidal phase than during the start of the tidal phase. For flood the oblique flow is not present. A hydrodynamic model (Delft 3D) of the Eastern Scheldt estimated that the flow angle can be as high as $31^{\circ}$ to the axis of the turbines at $200 \mathrm{~m}$ from the barrier for the low heads at the start of the ebb phase. For the higher heads and at the end of the ebb phase the angle is approximately $6^{\circ}$. An oblique approach flow leads to a reduced power production, particularly in turbine 5 .

\section{Thrust measurements}

Thrust measurements have been performed by Tocardo on the 3 th and 5 th turbine in the barrier. Similar to the

TABLE 3

SUMMARY OF THE MEASURED THRUST OF THE TURBINES

\begin{tabular}{lllllll}
\hline \multirow{2}{*}{ Tide } & Case & $\begin{array}{l}\text { T1 } \\
{[\mathrm{kN}]}\end{array}$ & $\begin{array}{l}\text { T2 } \\
{[\mathrm{kN}]}\end{array}$ & $\begin{array}{l}\text { T3 } \\
{[\mathrm{kN}]}\end{array}$ & $\begin{array}{l}\text { T4 } \\
{[\mathrm{kN}]}\end{array}$ & $\begin{array}{l}\text { T5 } \\
{[\mathrm{kN}]}\end{array}$ \\
\hline \multirow{2}{*}{ Ebb } & WT.1 & n/a & n/a & -20.00 & $\mathrm{n} / \mathrm{a}$ & -25.43 \\
& WT.2 & n/a & n/a & -33.97 & n/a & -40.06 \\
\multirow{2}{*}{ Flood } & WT.3 & n/a & n/a & 43.25 & n/a & 45.39 \\
& WT.4 & n/a & n/a & 105.04 & n/a & 117.68 \\
\hline
\end{tabular}

power measurements, these measurements have been analysed and used as validation by the CFD model. The thrust is measured with thrust gauges, which are mounted on the strut of the turbine. The values as presented in Table 3 are analysed based on the head differences over the barrier, similar to the power and ADCP measurements

\section{CFD simulations}

The simulations have been performed using the Star$\mathrm{CCM}+\AA$ software, version 11.02 .10 , a proprietary and

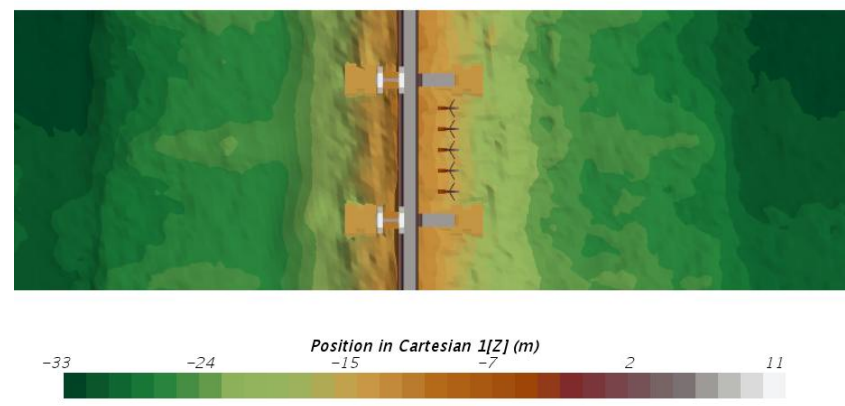

Fig. 4. Contour plot of the bed elevation. Dimension are with reference to NAP 
commercial CFD package. Star-CCM+ is able to solve the Navier-Stokes equations for mass and momentum in a three-dimensional domain, both steady-state or transient. The package also includes its own meshing algorithm. Different types of boundary conditions, numerical schemes and turbulence models are available.

Star-CCM+ has been used successfully by Deltares in recent years for the simulation of free surface flow in and around hydraulic structures, e.g. shipping locks and sluices, sewage systems and tidal energy applications. Previous validation of flows around tidal turbines [3] and the Eastern Scheldt Barrier [4] have also been performed with this software.

The flow through the barrier is simulated including the free surface. The highly detailed pillar and sill geometry result in an extremely turbulent flow downstream of the barrier and in this work an eddy-resolving turbulence model is used.

For the CFD simulations the water levels are considered to be constant, which has the effect of excluding tidal inertia effects from the model. This is further addressed in the discussion section.

\section{NUMERICAL SETUP}

\section{E. General model settings}

The equations are solved in transient form, with 1st order temporal discretization, and a segregated pressurebased solver. The equations are discretized on a structured 3D grid. The Finite Volume method is used with 3rd order combination of MUSCL and Central Difference for the discretisation of the advection terms. To model turbulence near the turbines and near the sill of the barrier, Improved Delayed Detached Eddy Simulation (IDDES) turbulence model has been applied. This model uses a Large-Eddy Simulation approach in the bulk flow and a ReynoldsAveraged Navier Stokes approach in the near wall region. The near wall model uses the SST k-Omega model with wall functions. An LES model is used for the vast majority of the domain. To model the free surface air and water are included as immiscible phases in the Volume of Fluid (VOF) model. A time step of 0.05 seconds is used for the final simulations although some of the spin-up of the simulations is performed with a larger time step 0.1-0.5 s. In all cases the time step and mesh are sufficient to achieve a sharp interface for the volume fraction of water between air and water, this interface being no more than 1 or 2 cells in the vertical at all locations.).

\section{F. Geometry}

The geometry of the CFD simulations encompasses a region approximately $200 \mathrm{~m}$ upstream and $200 \mathrm{~m}$ downstream of the barrier. The bathymetry (see Figure 4) has been generated from multibeam data (resolution $0.5 \mathrm{~m}$ ) of the Eastern Scheldt region of 2017 provided by Rijkswaterstaat and converted to an stl file, with a resolution of $2 \mathrm{~m}$. It is integrated with the 3D CAD of the barrier and the turbines.
TABLE 4

SUMMARY OF THE BOUNDARY CONDITIONS FOR THE CFD

\begin{tabular}{ll}
\hline Boundary & Conditions \\
\hline $\begin{array}{l}\text { North Sea / Eastern } \\
\text { Scheldt }\end{array}$ & Inflow profile and water levels \\
Bed & No-slip wall (smooth - no roughness) \\
Barrier & No-slip wall with roughness \\
Sides (in breadth) & Symmetry \\
Top & Atmospheric pressure \\
\hline
\end{tabular}

The geometry encompasses one full port of the storm surge barrier (Roompot 8) and half of the neighbouring ports on each side. The geometry has been updated and verified based on the as built drawings from Rijkswaterstaat and photographs of the structure during installation.
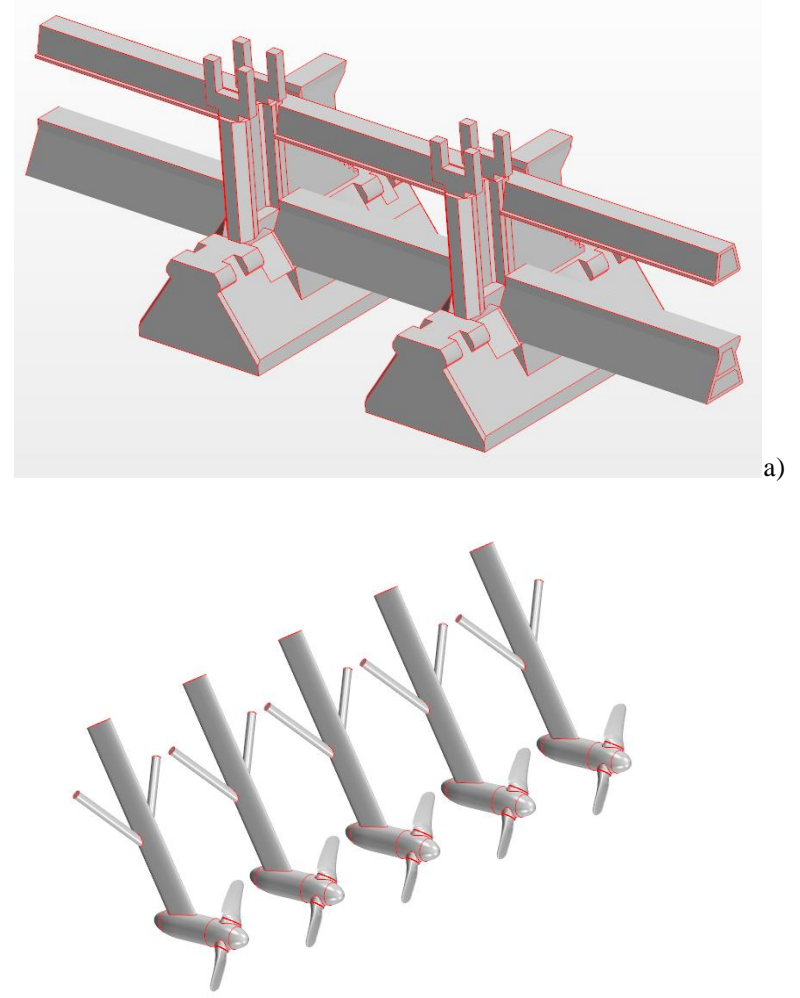

b)

Fig. 5. 3D CAD view of the geometry of a) the barrier as seen from the North Sea, and, b) the five turbines with support structure

The turbine and array geometries have been provided by Tocardo, the manufacturer and operator of the turbines. Each turbine has two blades and is mounted on a support from above. There are 5 turbines in the port of Roompot 8 , each with a diameter of $5.2 \mathrm{~m}$. The distance between the axes of each turbine is $6.7 \mathrm{~m}$. The configuration can be seen in Figure 5 with all turbine blades in the same orientation. In the simulations the turbines do not rotate in sync but at different (but constant) rotating speeds from each other. After some spin-up time the turbines are at very different orientations from each other at any given time. A rotating zone made of a cylinder of $6 \mathrm{~m}$ diameter and $3.2 \mathrm{~m}$ length is located around each turbine hub. Ideally a larger rotating zone should be used for CFD calculations so that 
the interpolation between the rotating zone and the stationary zone (occurring at the interaction surface between the two zones at each time step) is performed at a location where the gradients of the flow are small and the numerical errors in interpolation have a small effect. However, for these simulations the rotating zone around the turbines is limited in size owing to the requirement that they don't overlap with each other or have a very small gap between them where cell quality would be low. A zone of $6 \mathrm{~m}$ diameter has been used because it allows for good quality cells between the different rotating zones and is therefore considered acceptable for this study.

\section{G. Mesh}

The mesh has been generated in Star-CCM+ using multiple areas of mesh refinement. The largest cells in the domain are in the far field near the boundaries and are cube cells of size $1.2 \mathrm{~m}$. Given that the water depth is approximately $30 \mathrm{~m}$ in this region, this gives a minimum of 20 cells in the vertical. The mesh is refined in the region $60 \mathrm{~m}$ upstream and downstream of the barrier such that the cells in this region become slightly elongated with the longitudinal and transverse dimension still $1.2 \mathrm{~m}$, but with vertical dimension $60 \mathrm{~cm}$. The water depth in this region can be as low as $18 \mathrm{~m}$ but still this mesh gives approximately 30 cells in the vertical. Around the barrier sill itself the cells are refined further and are again cubic with dimension $16 \mathrm{~cm}$. The height of the opening above the sill is approximately $10.5 \mathrm{~m}$ but the water depth can be 9 $\mathrm{m}$. In any case the mesh has at least 40 cells in the vertical. The total number of cells for simulations with turbines is approximately 55 million and the simulations took 4 weeks using 40 cores on a cluster of an Intel Xeon E3-1276 v3 processors of 3.6 Ghz.

\section{H. Boundary conditions}

The boundary conditions are a combination of water levels and inlet velocity along with no-slip boundaries for the wall boundaries at the barrier and bed. The conditions at the inlet and outlet boundaries are constant throughout

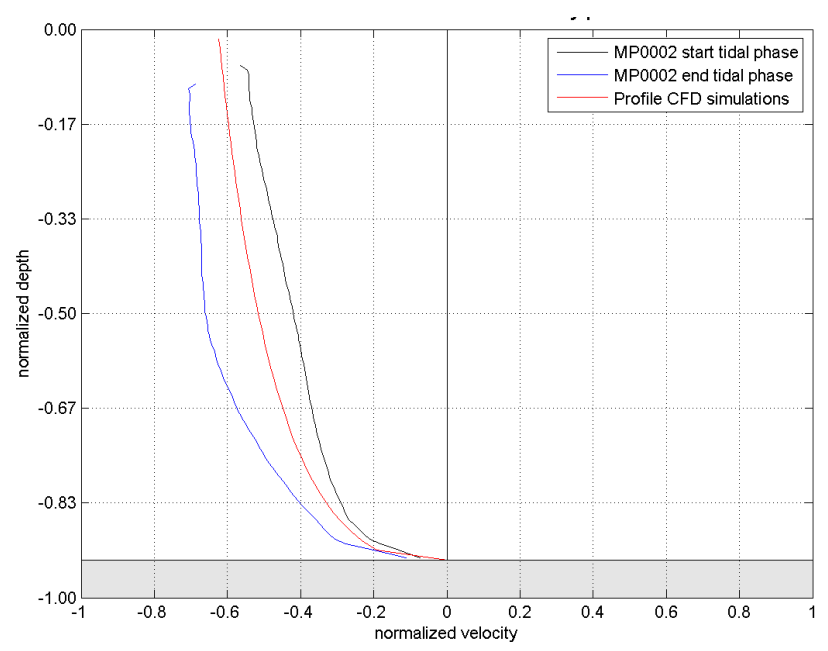

Fig. 6 Measured profile at MP0002 versus logarithmic vertical profile used in CFD the simulation giving a flow field without inertial effects associated with a varying tidal water level.

\section{1) Inflow velocity profile}

ADCP data of the velocity profile in the Eastern Scheldt is available for a number of measurement points. MP0002 is in the Eastern Scheldt $750 \mathrm{~m}$ from the barrier and at a location where the bathymetry is representative for the inflow conditions to Roompot 8. A comparison of measured velocity profiles in the Eastern Scheldt shows that a logarithmic profile is representative.

Figure 6 shows comparison of the measured profile during Ebb which would be representative of the inflow condition for the CFD model, along with an example of the logarithmic profile used for the CFD (scaled to the depth at that location). The measurements show a variation in the profile between the start of the tidal phase and the end of the tidal phase due to inertia of the tide. The CFD profile is between these two measured profiles and is therefore a good model of the average inflow conditions at the barrier.

\section{2) Water levels}

Water levels are set at the downstream boundaries with a profile of the volume fraction of water, where the volume fraction is 1 below the water level and 0 above it. The downstream boundary is the Eastern Scheldt for flood cases and the North Sea for Ebb cases. An initial water level is also set for the upstream boundary in the same way along with a velocity profile. This initial water level may not be consistent with the discharge through the barrier and the downstream water level and therefore the upstream water level varies during the simulation. In order to have results for the desired set of conditions in Table 2, the velocity profile is scaled to adjust the discharge until the achieved upstream water level is within $1 \mathrm{~cm}$ of the desired level. This water level is always averaged over the breadth of the domain and then time-averaged.

\section{3) Wall boundaries}

The barrier itself includes the sill and the pillars which are of concrete. They are modelled as no-slip walls with a roughness of worn concrete $(1 \mathrm{~cm})$. The bed includes the small-scale variations of the bed protection and seabed which have been captured by the multibeam data of $0.5 \mathrm{~m}$ resolution and has been modelled as a no-slip wall without additional roughness. The sides of the domain located at the halfway point between the two pillars in gate 7 and 9 so that a symmetry boundary condition can be used.

\section{4) Turbine rotation rate}

The rotation speed of the turbines is applied to the model as an input parameter. The rotation speeds are based on measured RPMs at the turbines. The rotation speed in the simulations is therefore chosen to correspond to the head difference of the simulation; a different speed is therefore given to each turbine (for more information see [31]). A summary of the rotation speeds used in the simulations is given in Table 5 . 


\section{RESULTS}

\section{Discharge coefficients}

The discharge through the barrier depends on resistance of the barrier and the head difference across the barrier. The discharge coefficient gives the relation between the head and the discharge for a given situation. It is dependent on the cross section: in case of the Eastern Scheldt barrier this is also dependent on the water level. The discharge can be described by the following formula.

$$
Q=\mu A \sqrt{2 g \Delta h}
$$

In which $Q$ is discharge $\left[\mathrm{m}^{3} / \mathrm{s}\right], \mu$ discharge coefficient [ - ], A the wetted cross-sectional area in the port, $\left[\mathrm{m}^{2}\right], \mathrm{g}$ gravitational constant $\left[\mathrm{m} / \mathrm{s}^{2}\right]$ and $\Delta \mathrm{h}$ water level difference [m].

The discharge coefficients from the simulations were calculated for each CFD case. A distinction is made for a coefficient over the whole domain and between each port of the barrier. For the simulations without turbines these should be identical because of the symmetry in the geometry and boundary conditions. The Star-CCM+ monitors give a constant discharge at the inlet boundary,

TABLE 6

RESULTS OF THE DISCHARGE COEFFICIENTS

\begin{tabular}{lllll}
\hline Tide & Case & $\begin{array}{l}\text { Head } \\
{[\mathrm{m}]}\end{array}$ & $\begin{array}{l}\mu \text { Gate } \\
\# 08\end{array}$ & $\mu$ Side \\
\hline \multirow{2}{*}{ Ebb } & NT.1 & -0.20 & 0.96 & 0.98 \\
& NT.2 & -0.32 & 0.98 & 0.99 \\
\multirow{2}{*}{ Flood } & NT.3 & 0.20 & 0.86 & 0.87 \\
& NT.4 & 0.55 & 0.88 & 0.89 \\
\multirow{2}{*}{ Ebb } & WT.1 & -0.20 & 0.93 & 0.97 \\
\multirow{2}{*}{ Flood } & WT.2 & -0.32 & 0.92 & 0.98 \\
& WT.3 & 0.20 & 0.85 & 0.85 \\
& WT.4 & 0.55 & 0.88 & 0.88 \\
\hline
\end{tabular}

NT represents No Turbines, WT represents With Turbines

owing to the specification of the inlet profile there. The discharge at the outlet boundary varies during the simulation owing to the unsteadiness of the flow. The value reported in Table 6 is based on a monitor for discharge through a vertical cross-section at the barrier which is averaged over $100 \mathrm{~s}$ of simulation time after reaching a statistically steady-state.

For the ebb cases the discharge coefficient $(\mu)$ is almost identical between the cases 1 and 2 . The maximum difference is $2 \%$. This can be attributed to the very similar water levels upstream in each case (the difference is only $13 \mathrm{~cm}$ ) and the small difference in head (only $12 \mathrm{~cm}$ ). For the flood cases the upstream water level varies between the cases by $1.69 \mathrm{~m}$. For a barrier of this type with a lintel support which is submerged in water for the higher water levels the discharge coefficient is expected to be dependent on water levels as well as geometry. However, even in this case the difference is not large between case 3 and 4 , approximately $3 \%$.
The effect of the presence of the tidal turbines can be determined by comparing the simulations with and without turbines for the coefficient through Gate Roompot 8 . The discharge capacity hardly changes during flood and decreases by about $5 \%$ during ebb. The main reason for this is the fact that the turbines are positioned upstream of the barrier sill during ebb and sufficiently far downstream of the barrier sill during flood. During ebb, the turbines are blocking the flow towards the barrier, while during flood the influence of the turbines on the flow becomes effective after the flow has passed the narrowest cross section of the gate (above the sill).

\section{J. Velocity profiles}

\section{1) Barrier without turbines}

The ADCP measuring devices for the vertical profiles were mounted on the Eastern Scheldt face of the barrier sill. In the Ebb case this is in a location upstream of the point of flow separation. The vertical velocity profile (Figure 7) shows therefore simply an approximately logarithmic profile with a clear boundary layer starting from the height of the top of the sill. The measurements are split between a profile from the start of the tidal phase and that from the end of the tidal phase. The difference between the two profiles is due to inertia in the Eastern Scheldt.

The CFD simulations are made with constant boundary conditions (water levels) and the results are taken once the flow field has reached an equilibrium (a statistically steady

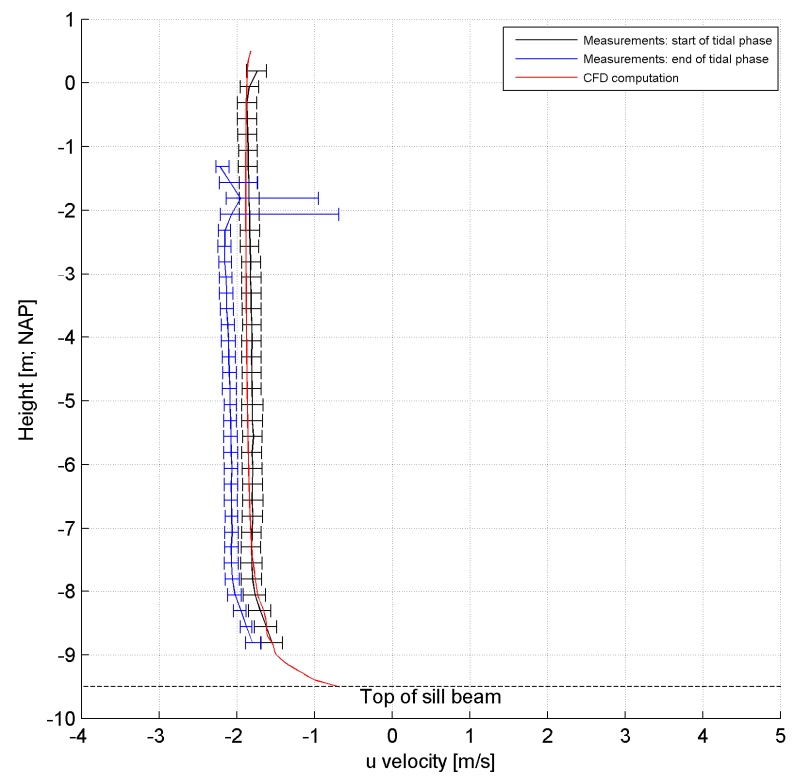

Fig. 7 Vertical ADCP profile from the measurements without turbines (in blue) and the CFD (in red) - Ebb Case NT.1

TABLE 5

SUMMARY OF THE ROTATION RATES OF THE TURBINES

\begin{tabular}{lllllll}
\hline \multirow{2}{*}{ Tide } & Case & $\begin{array}{l}\text { T1 } \\
{[\mathrm{rpm}]}\end{array}$ & $\begin{array}{l}\text { T2 } \\
{[\mathrm{rpm}]}\end{array}$ & $\begin{array}{l}\text { T3 } \\
{[\mathrm{rpm}]}\end{array}$ & $\begin{array}{l}\text { T4 } \\
{[\mathrm{rpm}]}\end{array}$ & $\begin{array}{l}\text { T5 } \\
{[\mathrm{rpm}]}\end{array}$ \\
\hline \multirow{2}{*}{ Ebb } & WT.1 & -24.33 & -24.03 & -23.03 & -23.66 & -21.88 \\
& WT.2 & -31.29 & -31.17 & -30.52 & -30.97 & -30.36 \\
\multirow{2}{*}{ Flood } & WT.3 & 34.95 & 35.42 & 34.50 & 35.07 & 35.14 \\
& WT.4 & 44.57 & 44.86 & 44.47 & 44.61 & 44.66 \\
\hline
\end{tabular}


state), this means that the CFD results are free from inertia. It is therefore expected that the CFD profile should fall between the two measured profiles. For this vertical profile

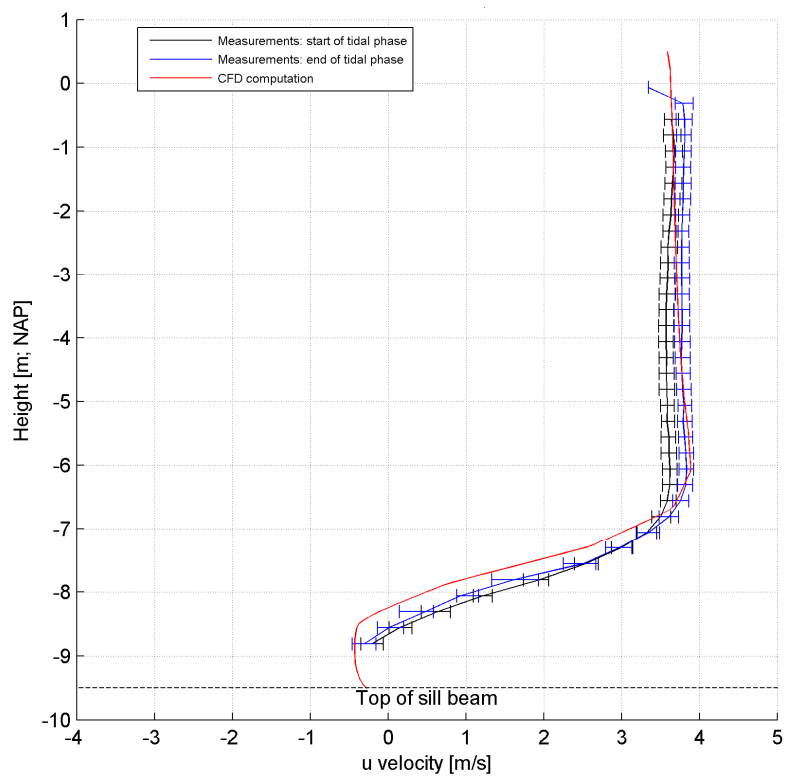

Fig. 8 Vertical ADCP profile from the measurements without turbines (in blue) and the CFD (in red) - Flood Case NT.4

of the ebb case NT.1 this is the case. The agreement with the numerical model is therefore considered good.

In the flood case the ADCP is located downstream of the sill and therefore is in the recirculation zone. The comparison of the CFD results with the measurements is shown in Figure 8. In this case the variation between the start of the tidal phase and the end of the tidal phase in the measurements is small and the velocity in the bulk of the flow is predicted very well by the CFD model. The size of the recirculation zone is slightly larger in the CFD than in the measurements. The horizontal flow profile (not shown) has similar characteristics to that in the ebb case and the agreement with CFD is equally good.

\section{2) Barrier with turbines}

For the ebb case (Figure 9) the inflow profile is at the top of the figure. This shows a region of rising speed (because of the coordinate system used the velocity here is negative and becomes more negative as it accelerates towards the barrier). The turbines are located upstream of the barrier, so the velocity magnitude drops in front of the barrier in the wake of the turbines. Note that for the simulation without the turbines the flow accelerates all the way to the sill and beyond, owing to the contraction of the flow which continues downstream of the sill in that case. Downstream of the turbines the velocity recovers. The agreement with the measurements is good although downstream of the turbines the uncertainty in the measurements is large. Upstream of the turbines the CFD simulations show a small underestimation of the velocity. Also, the CFD simulation with turbines shows lower velocity magnitudes than the simulation without turbines. This is owing to the difference in discharges in the two simulations owing to the extra resistance of the turbines (the profile is insensitive to the exact location in the vertical at which it is made). A slight underestimation of the velocity magnitude in the

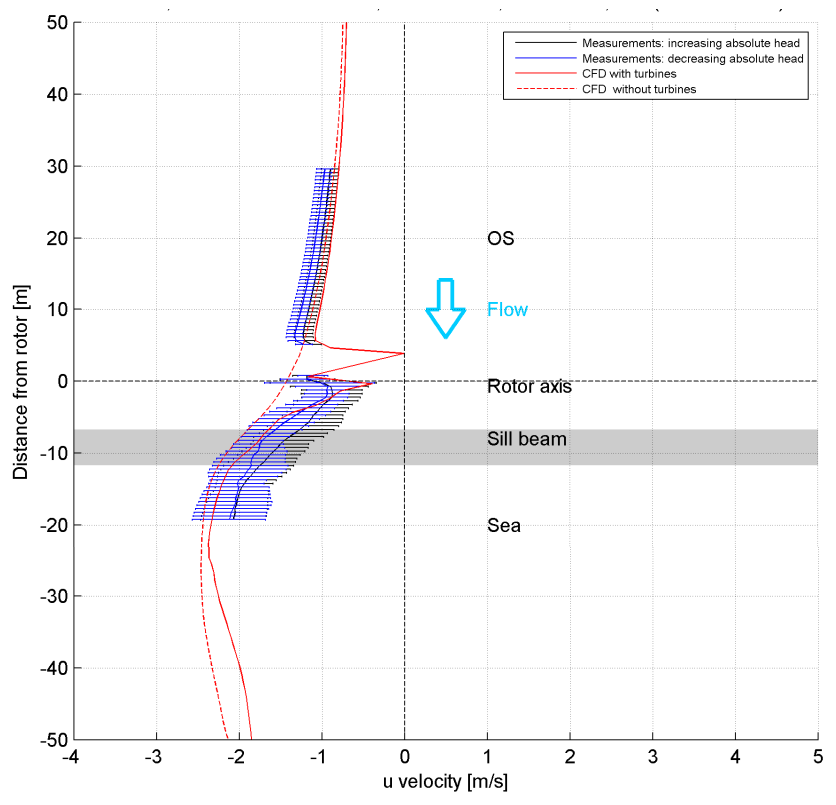

Fig. 9 Longitudinal ADCP profile from the measurements with turbines (in blue) and the CFD (in red) - Ebb Case WT.1

CFD when compared to the measurements could also suggest that the discharge is underestimated by the CFD.

For the flood case (Figure 10) the inflow profile is at the bottom of the graph showing the flow acceleration towards the barrier. In the flood case the velocity magnitude is lower compared to the measurements and the difference is greater than in the ebb case. The difference with the simulation without turbines is less in this case but is still consistent with extra resistance from the turbines. However, even the CFD simulation without turbines shows lower inflow velocities than the measurements of velocity with turbines for the same case. This is inconsistent and given that the velocities without turbines have been well validated against the 2011 measurements

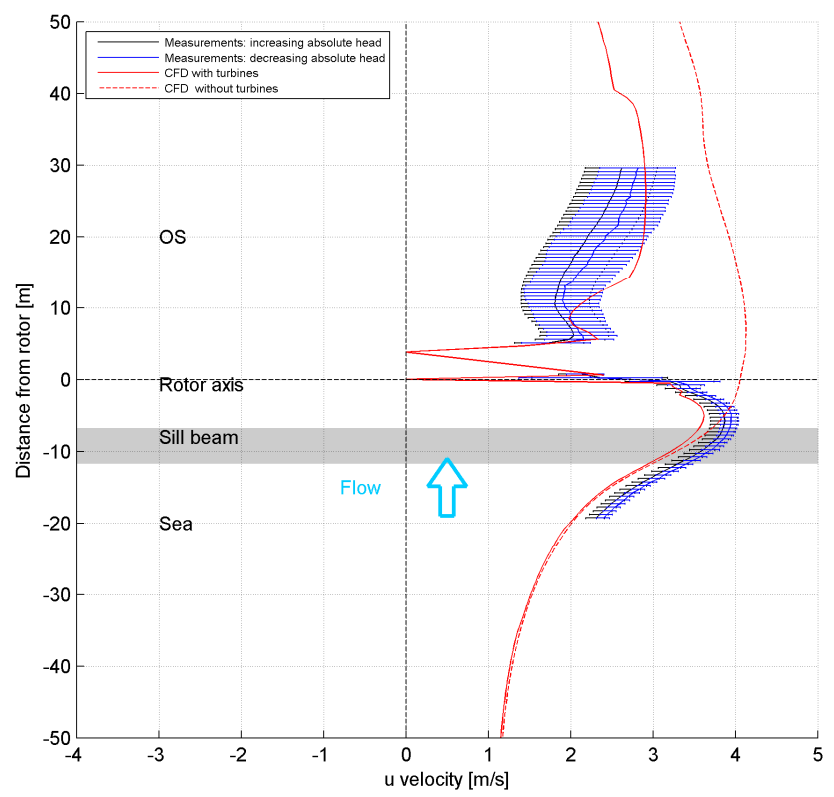

Fig. 10 Longitudinal ADCP profile from the measurements with turbines (in blue) and the CFD (in red) - Flood Case WT.4 
this throws some doubt on the absolute values of the 2016 measurements. In the analysis of the measurements [31], it was observed that the flow velocity during flood is about $5-10 \%$ larger for the situation with turbines than for the situation without turbines, whilst the opposite would be expected. The measurements with turbines are therefore concluded to show values that are too high.

In the wake region the recovery of the velocity is faster in the CFD model than in the measurements. For the flood case the wake region is much larger than in the ebb case because the flow is not subsequently squeezed through the barrier (see Figure 11), although note that the ADCP in the wake during ebb is not in line with the turbine axis (for flood it is). The recovery is not complete after $50 \mathrm{~m}$ (the
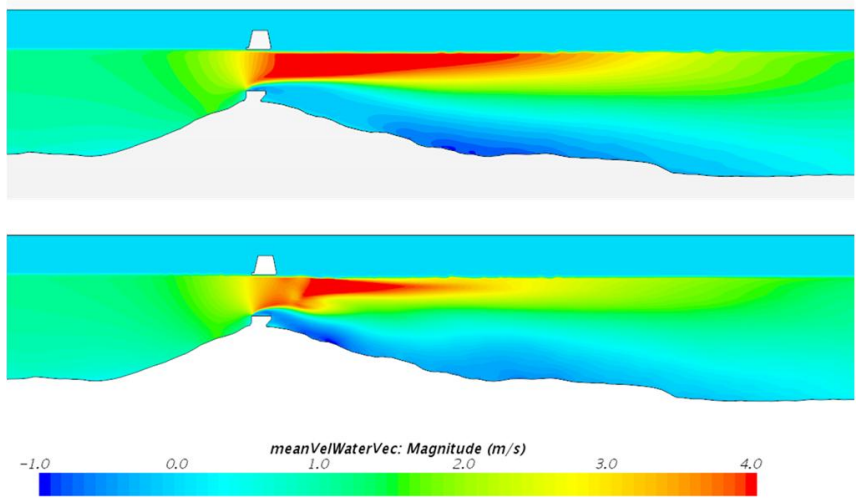

Fig. 11 Mean velocity for a vertical cross section between the turbines for flood case 4 without turbines (upper figure) and with turbines (lower figure). Only a detail around the sill is shown.

CFD domain extends $200 \mathrm{~m}$ downstream of the barrier but only $50 \mathrm{~m}$ are plotted in the figure).

The agreement of the CFD with the measurements is acceptable. Some of the details of the flow patterns are not predicted correctly, such as the distance of the wake recovery and from the comparison of the velocity profiles it can be concluded that the CFD slightly underestimates the discharge. This could be attributed to the lack of sufficient mesh resolution in the wake region to model the turbulence in this region.

\section{K. Turbine power}

Tocardo controls the operation of the turbines in the Eastern Scheldt Storm Surge Barrier based on the rotational speed of the turbine. The rotational speed of the turbine will be tuned in such a way that the maximum amount of energy can be subtracted from the turbine. This

TABLE 7

SUMMARY OF THE SIMULATED POWER OF THE TURBINES (MEASURED IN BRACKETS)

\begin{tabular}{lllllll}
\hline \multirow{2}{*}{ Tide } & \multirow{2}{*}{ Case } & $\begin{array}{l}\mathrm{T} 1 \\
{[\mathrm{~kW}]}\end{array}$ & $\begin{array}{l}\mathrm{T} 2 \\
{[\mathrm{~kW}]}\end{array}$ & $\begin{array}{l}\mathrm{T} 3 \\
{[\mathrm{~kW}]}\end{array}$ & $\begin{array}{l}\mathrm{T} 4 \\
{[\mathrm{~kW}]}\end{array}$ & $\begin{array}{l}\mathrm{T} 5 \\
{[\mathrm{~kW}]}\end{array}$ \\
\hline Ebb & WT.1 & 9.1 & 9.8 & 10.6 & 10.7 & 12.0 \\
& & $(17.2)$ & $(16.1)$ & $(14.6)$ & $(15.6)$ & $(13.2)$ \\
& \multirow{2}{*}{ WT.2 } & 19.8 & 20.8 & 22.2 & 22.5 & 24.8 \\
& & $(36.4)$ & $(34.9)$ & $(33.5)$ & $(34.8)$ & $(33.0)$ \\
Flood & \multirow{2}{*}{ WT.3 } & 49.0 & 48.4 & 48.6 & 48.4 & 48.5 \\
& & $(50.5)$ & $(51.1)$ & $(48.1)$ & $(50.2)$ & $(51.1)$ \\
& \multirow{2}{*}{ WT.4 } & 218.2 & 201.5 & 197.9 & 199.4 & 208.8 \\
& & $(220.0)$ & $(223.3)$ & $(214.1)$ & $(217.4)$ & $(222.0)$ \\
\hline
\end{tabular}

means that the ADCPs are not used to control the turbine operation.

In the CFD model, the rotational speed of the turbines is used as an input parameter. Together with the torque of the turbine, the power is calculated via the formula: $P=\tau \omega$, in which $\tau$ is the torque $(\mathrm{Nm})$ and $\omega$ is the angular velocity $[\mathrm{rad} / \mathrm{s}]$. The generated power is compared with the measured power from Tocardo. The measured power is the power that has been delivered to the rotor after correction for the system losses. Tocardo provided a conversion relation between the grid power and the power on the rotor. Due to energy losses to the system, the power on the rotor is approximately $10 \%$ higher.

In Table 7, the obtained power by the CFD model is presented. The deviation on the mean velocity for the higher power output cases is below $10 \%$. It has to be noted that the standard deviation for the modelling results is in the order of $5-10 \%$ of the mean power. For the

TABLE 8

SUMMARY OF THE SIMULATED THRUST OF THE TURBINES (MEASURED IN BRACKETS)

\begin{tabular}{|c|c|c|c|c|c|c|}
\hline Tide & Case & $\begin{array}{l}\mathrm{T} 1 \\
{[\mathrm{kN}]}\end{array}$ & $\begin{array}{l}\mathrm{T} 2 \\
{[\mathrm{kN}]}\end{array}$ & $\begin{array}{l}\text { T3 } \\
{[\mathrm{kN}]}\end{array}$ & $\begin{array}{l}\mathrm{T} 4 \\
{[\mathrm{kN}]}\end{array}$ & $\begin{array}{l}\mathrm{T} 5 \\
{[\mathrm{kN}]}\end{array}$ \\
\hline \multirow[t]{2}{*}{$E b b$} & WT.1 & -12.2 & -12.8 & $\begin{array}{l}-13.4 \\
(-20.0)\end{array}$ & -13.5 & $\begin{array}{l}-14.4 \\
(-25.4)\end{array}$ \\
\hline & WT.2 & -23.1 & -23.9 & $\begin{array}{l}-24.8 \\
(-34.0)\end{array}$ & -25.1 & $\begin{array}{l}-26.5 \\
(-40.1)\end{array}$ \\
\hline \multirow[t]{2}{*}{ Flood } & WT.3 & 38.5 & 38.6 & $\begin{array}{l}38.5 \\
(43.2)\end{array}$ & 38.6 & $\begin{array}{l}38.5 \\
(45.4)\end{array}$ \\
\hline & WT.4 & 114.6 & 111.4 & $\begin{array}{l}110.6 \\
(105.0)\end{array}$ & 110.9 & $\begin{array}{l}113.5 \\
(117.7)\end{array}$ \\
\hline
\end{tabular}

measurements, the standard deviation of the power is in the order of $10-20 \%$, with lower standard deviations for the cases with the larger head difference. Based on this analysis, it is concluded that the CFD model represents the measured power well.

\section{Turbine thrust}

The thrust, which is obtained from the CFD model is presented in Table 8. The differences with the measured values is approximately $10 \mathrm{kN}$. For the case with higher forcing on the turbines WT.4, the relative difference is maximum $5 \%$ of the measured thrust. Similar to the power, the standard deviation of the modelling results is $5 \%$, while the standard deviation of the measurements is in the order of $10-30 \%$. Where the cases with the lower head difference show the larger standard deviations. From this analysis, it is concluded that the CFD model represents the measured thrust sufficiently accurately.

\section{DISCUSSION}

\section{Validation of the model}

The CFD model has been validated against field measurements taken from ADCPs mounted at the barrier during operation. The agreement in velocity at the ADCP profile locations is good for the cases and head differences studied. The agreement is better for the ADCP measurements taken in the situation without turbines. For 
the situation with turbines the inflow velocities are slightly underpredicted. This could indicate that the discharges are also slightly underpredicted in the case with turbines. However, it has to be noted that the field measurements of the situation with turbines show about 5-10\% higher velocities than for the situation without turbines. This estimate is made by comparing the velocities measured at the sill without turbines, but at the height of the turbine axis, with the subsequent measurements when the turbines are installed. Similarly, the details of some of the profiles, the size of the recirculation zone and the size of the wake recovery zone, show some discrepancies but for the bulk parameter of a discharge coefficient this is of less importance. Also, in general the good agreement between the measurements and the CFD give confidence that the quality of the predicted flow field is high.

The predictions of the power and thrust from the turbines are validated as well. For both parameters, the standard deviation of the measurements is significant (between $10 \%$ and $30 \%$ ). The agreement of the CFD model with the measurements at the high flow rate (WT.4) is quite good $(<10 \%)$.

\section{$N$. Inclusion of rotating zones around the turbines}

The largest uncertainty in the results of the CFD simulations is created by the rotating zones around the turbines. The earlier validation [2] of the CFD model with turbines was performed with a larger rotating zone around the turbines than was possible to apply in these simulations. A larger zone is generally preferable because it allows the interpolation between rotating and stationary zones to be made at a location where the gradients are small and the numerical errors will similarly be smaller. For the simulations of 5 turbines in a row in the opening of the barrier it is not possible to create a larger zone. Similarly, for the flood case, the location of the rotating zone in a region of very high gradients downstream of the flow separation at the sill, makes the numerical errors of interpolation greater. The expected effect of this is to increase numerical diffusion which is a form of extra resistance in simulations which are not fully resolved.

The inclusion of the rotating turbines in the simulations is state-of-the-art (see discussion of literature in Section 1.1). The validation performed here with the turbines shows that this model is possible of generating validated mean profiles whilst still resolving a large proportion of the unsteady turbulence generated by the turbines and thereby giving insights into the true effect of the turbines on the downstream flow.

\section{O. Biofouling of the Eastern Scheldt Barrier}

During installation of the horizontal and vertical ADCP's in 2011 by Partrac, biofouling was observed on the sill. A layer of approximately $10 \mathrm{~cm}$ of mussels had to be removed from the sill before installation of the ADCP equipment. This layer of biofouling has not been included in the CFD simulations, while it may have an effect on the details of flow through the barrier.
Some simulations with different roughness were made during the validation process of the model but adding a roughness as much as $10 \mathrm{~cm}$ is not possible in the current setup because in the model currently used the roughness is limited to the size of the first cell near the wall. An investigation of other methods to include roughness in the model was not carried out.

\section{P. Dynamic effects in the Eastern Scheldt}

From the measurements it became clear that due to inertia, the velocities are much higher at the end of the tidal phase than at the beginning of the tidal phase. This effect is not included in the CFD model because the water levels were imposed as constant boundary conditions. The CFD simulations also do not include the oblique approach flow which is present at the start of the tidal phase for the ebb cases. This oblique flow is the result of the turning of the tide in the local geometry of the Eastern Scheldt. This oblique approach flow angle could have played a role in the validation of the power measurements.

\section{CONCLUSION}

The CFD simulations performed of the Eastern Scheldt Barrier were conducted for the purpose of the prediction of discharge capacity and flow patterns downstream of the barrier. With this objective in mind the following conclusions can be drawn:

\section{Q. Model is validated for discharge coefficients:}

The agreement between the CFD and ADCP field measurements of velocity profiles is good. The small discrepancy in a number of details is not sufficient to result in significant differences in the total flow through the barrier. The agreement in the profiles is also not sensitive to the exact location in the domain at which the profile is drawn. This gives confidence that the comparison made is valid for a large part of the flow field. For the cases with turbines it appears that the inflow velocities (and consequently discharges) are slightly underpredicted. However, it is unclear if this is caused by the numerical model or by the flow measurements, which have shown that the upstream flow velocities are higher for the situation with turbines than without turbines. It is concluded that the developed model is suitable for an assessment of the effect of the turbines on the discharge coefficient.

\section{R. Model validation for power and thrust}

The discrepancy between the CFD calculated turbine power and the measured turbine is small for high discharges and within the ranges of uncertainty. For simulations where the agreement in inflow velocity profiles is better the agreement with the measured power is also improved. This means the model should perform well for the prediction of the optimal location of the turbines in the flow field for power generation. 


\section{S. Effect of turbines on discharge coefficient}

The turbines have only a small effect on the discharge coefficients. For the ebb case the reduction in discharge coefficient between simulations without and with turbines is approximately $5 \%$. For the flood cases the reduction was negligible in both cases but this is likely within the range of accuracy of the simulations. The small effect on the discharge coefficient for flood is attributed to the fact that the turbines are placed sufficiently far downstream of the sill. During ebb, the turbines are upstream of the barrier, which causes a reduced discharge coefficient.

The relative small effects on the discharge coefficients of the barrier gate in question imply that the effects of the tidal array on the environment (currents, tidal ranges, tidal flats) of the Eastern Scheldt estuary will not be large. The work on the environmental effects will be presented separately.

\section{ACKNOWLEDGEMENT}

The work is part of the Dutch Marine Energy Centre (DMEC) project funded by the European Regional Development Fund (ERDF) and co-financed by the Province of Noord-Holland. Tocardo Tidal Power BV is gratefully acknowledged for the permission to publish the results of the ADCP, thrust, power and RPM measurements.

\section{REFERENCES}

[1] Rijkswaterstaat, "Design Plan Oosterschelde Storm Surge Barrier: Overall design and design philosophy," Rijkswaterstaat, Rotterdam, The Netherlands1994.

[2] A. Tralli, A. Bijlsma, W. te Velde, and P. de Haas, "CFD Study on Free-Surface Influence on Tidal Turbines in Hydraulic Structures," Proc. of the ASME 34th International Conference on Ocean, Offshore and Artic Engineering, no. OMAE2015-41187, 2015.

[3] A. Bijlsma, A. Tralli, W. Verbruggen, and P. De Haas, "Detailed dynamics of the Eastern Scheldt storm surge barrier: validation of a CFD approach," Proc. of the 4th International Symposium of Shallow Flows, 2017.

[4] W. M. J. Batten, A. S. Bahaj, A. F. Molland, and J. R. Chaplin, "The prediction of the hydrodynamics performance of marine current turbines," Renewable Energy, vol. 33, pp. 1085-1096, 2008.

[5] S. R. Turnock, A. B. Phillips, J. Banks, and R. Nicholls-Lee, "Modelling tidal current turbine wakes using a coupled RANSBEMT approach as a tool for analysing power capture of arrays of turbines," Ocean Engineering, vol. 38, pp. 1300-1307, 2011.

[6] C. H. Jo, J. Y. Yim, K. H. Lee, and Y. H. Rho, "Performance of horizontal axis todal current turbine by blade configuration," Renewable Energy, vol. 42, pp. 195-206, 2012.

[7] S. Gant and T. Stallard, "Modelling a tidal turbine in unsteady flow," Proc. 18th Int. Offshore and Polar Engineering Conference, pp. 473-480, 2008.

[8] W. M. J. Batten, M. E. Harrison, and A. S. Bahaj, "Accuracy of the actuator disc-RANS approach for predicting the performance and wake of tidal turbines," Phil Trans $R$ Soc A, vol. 371, no. 20120293, 2013.

[9] L. Myers and A. S. Bahaj, "Power output performance characteristics of a horizontal axis marine current turbine," Renewable Energy, vol. 31, pp. 197-208, 2005.

[10] L. Myers and A. S. Bahaj, "Wake studies of a 1/30th scale horizontal axis marine current turbine," Ocean Engineering, vol. 34, pp. 758-762, 2007.

[11] X. Sun, J. P. Chick, and I. G. Bryden, "Laboratory-scale simulation of energy extraction from tidal currents," Renewable Energy, vol. 33, pp. 1267-1274, 2008.
[12] L. Myers and A. S. Bahaj, "Experimental analysis of the flow field around horizontal axis tidal turbines by use of scale mesh disk rotor simulators," Ocean Engineering, vol. 37, no. 218-227, 2010.

[13] M. E. Harrison, W. M. J. Batten, L. Myers, and A. S. Bahaj, "A comparison between CFD simulations and experiments for predicting the far wake of horizontal axis tidal turbines," Proc. 8th European Wave and Tidal Energy Conference (EWTEC), 2010.

[14] M. J. Lawson, Y. Li, and D. Sale, "Development and Verification of a Computational Fluid Dynamics Model of a Horizontal Axis Tidal Current Turbine," Proc. 30th ASME Int. Conf. on Ocean, Offshore and Arctic Engineering, no. OMAE2011-49863, 2011.

[15] W. Otto, D. Rijpkema, and G. Vaz, "Viscous Flow Calculations on an Axial Marine Current Turbine," Proc. 31th ASME Int. Conf. on Ocean, Offshore and Arctic Engineering, no. OMAE201283452, 2012.

[16] A. Mason-Jones et al., "Non-dimensional scaling of tidal stream turbines," Energy, pp. 820-829, 2012.

[17] C. Frost, C. E. Morris, A. Mason-Jones, D. M. O'Doherty, and T. O'Doherty, "The effect of tidal flow directionality on tidal turbine performance," Renewable Energy, vol. 78, pp. 609-620, 2015.

[18] A. S. Bahaj, W. M. J. Batten, and G. McCann, "Experimental verification of numerical predictions for the hydrodynamic performance of horizontal axis marine current turbines," Renewable Energy, vol. 32, pp. 2479-2490, 2007.

[19] A. S. Bahaj, A. F. Molland, J. R. Chaplin, and W. M. J. Batten, "Power and Thrust measurements of marine current turbines under various hydrodynamic flow conditions in a cavitation tunnel and towing tank," Renewable Energy, vol. 32, no. 3, pp. 407-426, 2007

[20] J. Whelan, J. M. R. Graham, and J. Peiro, "A free-surface and blockage correction for tidel turbines," Journal of Fluid Mechanics, vol. 624, pp. 281-291, 2009.

[21] C. A. Consul, R. H. J. Willden, and S. C. McIntosh, "Blockage effects on the hydrodynamic performance of a marine cross-flow turbine," Phil Trans R Soc A, vol. 371, no. 20120299, 2013.

[22] T. Blackmore, W. M. J. Batten, and A. S. Bahaj, "Influence of turbulence on the wake of a marine current turbine simulator," Phil Trans R Soc A, vol. 470, no. 20140331, 2014.

[23] T. Blackmore, L. Myers, and A. S. Bahaj, "Effects of turbulence on tidal turbines: Implications to performance, blade loads and condition monitoring," International Journal of Marine Energy, vol. 14, pp. 1-26, 2016.

[24] M. J. Churchfield, Y. Li, and P. J. Moriaty, "A large-eddy simulation study of wake propagation and power production in an array," Phil Trans R Soc A, vol. 371, no. 20120421, 2013.

[25] T. Daly, L. Myers, and A. S. Bahaj, "Modelling of the flow field surrounding tidal turbine arrays for varying positions in a channel," Phil Trans R Soc A, vol. 371, no. 20120246, 2013.

[26] T. Stallard, R. Collings, T. Feng, and J. Whelan, "Interactions between tidal turbine wakes: experimental study of a group of three-bladed rotors," Phil Trans R Soc A, vol. 371, no. 20120159, 2013.

[27] A. Olczak, T. Stallard, T. Feng, and P. K. Stansby, "Comparison of a RANS blade element model for tidal turbine arrays with laboratory scale measurements of wake velocity and rotor thrust," Journal of Fluids and Structures, vol. 64, pp. 87-106, 2016.

[28] T. O'Doherty, A. Mason-Jones, D. M. O'Doherty, P. S. Evans, C. Wooldridge, and I. Fryett, "Considerations of a horizontal axis tidal turbine," Proc. Inst of Civil Engineers. Energy, vol. 163, no. EN3, pp. 119-130, 2010.

[29] U. Ahmed, I. Afgan, D. D. Apsley, T. Stallard, and P. K. Stansby, "CFD simulations of a full-scale tidal turbine: comparison of LES and RANS with field data," Proc. 11th European Wave and Tidal Energy Conference (EWTEC), 2015.

[30] M. Verbeek, R. J. Labeur, and W. Uijttewaal, "Field observations of rotor thrust and bypass-acceleration at a tidal fence," presented at the 6th Oxford Tidal Energy Workshop, Oxford, UK, 2018.

[31] W. Verbruggen, "Analysis ADCP data Eastern Scheldt Barrier with and without turbine deployment," Deltares2018. 